\title{
Cursos de mestrados no Brasil, na França e em Portugal: elementos de uma abordagem comparativa
}

\section{Masters courses in Brazil, France and Portugal: elements of a comparative approach}

\section{Los Másteres en Brasil, Francia y Portugal: elementos de un enfoque comparativo}

Lucília Regina de Souza Machado, doutora em Educação pela Pontifícia Universidade Católica de São Paulo (PUC-SP), pósdoutora em Sociologia do Trabalho pelo Institut de Recherches sur les Sociétés Contemporaines, França, e coordenadora do Programa de Pós-Graduação em Gestão Social, Educação e Desenvolvimento Local do Centro Universitário UNA. E-mail: Ismachado@uai.com.br.

Eloisa Helena Santos, doutora em Ciências da Educação pela Université Paris 8 Vincennes - Saint-Denis, França; pós-doutora em Sociologia do Trabalho pela Université Paris $X$ - Nanterre, França, e em Ergologia pela Universidade de Provence (UP), França, e professora do Programa de Pós-Graduação em Gestão Social, Educação e Desenvolvimento Local do Centro Universitário UNA. E-mail: eloisasantos@uaivip.com.br.

Adilene Gonçalves Quaresma, doutora em Educação pela Universidade Federal de Minas Gerais (UFMG) e professora do Programa de Pós-Graduação em Gestão Social, Educação e Desenvolvimento Local do Centro Universitário UNA. E-mail: adilenequaresma@gmail.com.

\section{Resumo}

Este artigo parte da constatação de que, no contexto da América Latina, existe uma lacuna na pesquisa educacional crítica relativa ao enfoque comparativo internacional e de que há um movimento recente 
de retomada dos estudos comparados como instrumento de apoio à decisão política, em face de problemas educacionais globalizados. Ele tem como objetivo estudar aspectos da organização e da oferta de cursos de mestrado no Brasil, na França e em Portugal. A abordagem comparativa se fez por meio da identificação da legislação e de dados estatísticos disponíveis e focalizou elementos que, por meio do olhar dirigido ao outro, tratam da construção da identidade dos cursos de mestrado nesses países, na perspectiva de contribuir com o aprimoramento desse nível de ensino e inspirar outros estudos e pesquisas sobre o tema.

Palavras-chave: Cursos de Mestrado. Abordagem Comparativa Internacional. Organização e Oferta de Mestrados.

\section{Abstract}

This article derives from the observation that there is a gap in critical educational research in the context of Latin America concerning the international comparative approach and that, due to the globalization of educational problems, there is a recent movement to resume comparative studies as a tool to support policy making. It aims to study aspects of the organization and availability of master courses in Brazil, France and Portugal. The comparative approach was developed through the identification of legislation and available statistical data. From the perspective of the other, the study focused on elements dealing with the identity construction of master courses in these countries in order to contribute to the improvement of this level of education and inspire other studies and investigations about the theme.

Keywords: Master Courses. International Comparative Approach. Organization and Availability of Masters.

\section{Resumen}

Este artículo parte de la constatación de que existe una brecha en la investigación educativa crítica en el contexto de América 
Latina, relativa el enfoque comparativo internacional y de que hay un movimiento reciente de reanudación de los estudios comparativos como una herramienta de apoyo a la decisión política ante problemas educativos globalizados. Su objetivo es estudiar los aspectos de la organización y de la oferta de másteres en Brasil, Francia y Portugal. El enfoque comparativo se realizó a través de la identificación de la legislación y de los datos estadísticos disponibles. A través de la mirada del otro, el estudio se centró en los elementos que se refieren a la construcción de la identidad de los másteres en estos países, con la expectativa de contribuir a la mejora de este nivel de educación e inspirar a otros estudios e investigaciones acerca del tema.

Palabras clave: Másteres. Enfoque Comparativo Internacional. Organización y Oferta de Másteres.

\section{Introdução}

Krawczyk (2013, p. 201) constata o afastamento, na América Latina, da pesquisa educacional crítica com relação ao enfoque comparativo internacional, fenômeno que decorreria da "forte associação [desse enfoque] com o paradigma positivista e com a política imperialista de desenvolvimento". Na atualidade, porém, segundo a autora, estaria ocorrendo uma reversão desse distanciamento, sob o impacto da importância dos estudos comparados como suporte à decisão política, em face de problemas educacionais globalizados. Essa é a razão que motivou as autoras deste artigo a estudarem aspectos da organização e da oferta de cursos de mestrado no Brasil, na França e em Portugal, países selecionados pela importância das relações históricas que têm com eles estudantes e professores brasileiros de pós-graduação. Abordar comparativamente a oferta e a organização de cursos de mestrado nesses três países ultrapassa a mera curiosidade. Segundo Ciavatta (2000, p. 198), o "processo de conhecimento do outro e de si próprio, nesta troca entre realidades culturais diversas, implica um confronto que vai além do mero conhecimento do outro. Implica a comparação de si próprio com aquilo que se vê no outro". Tal aprendizado motivou este estudo, sabendo-se que experiências educacionais não 
são transmitidas, mas podem incitar e incentivar reflexões e práticas, sobretudo quando se conhece seu contexto histórico nacional e suas condições objetivas de produção. O espaço deste artigo é limitado para abarcar com a devida pertinência tais correlações, mas suficiente para apresentar algumas dimensões comparativas dos cursos de mestrado dos três países, dimensões que instigam estudos mais aprofundados. Inicialmente, pode-se identificar as ancoragens de tais cursos, como apresentado a seguir.

Em 25 de maio de 1998, os ministros responsáveis pelo ensino superior da Alemanha, da França, da Itália e do Reino Unido, reunidos na Sorbonne, elaboram uma declaração comum que objetiva harmonizar a arquitetura do sistema europeu do ensino superior. Em seguida, a Declaração de Bolonha, de 19 de junho de 1999, dá continuidade ao encontro anterior e desencadeia o Processo de Bolonha, que cria o Espaço Europeu do Ensino Superior. Ele tem como princípio promover a atratividade desse sistema de ensino em escala mundial, de forma que viabilize a compatibilidade e a comparabilidade entre os sistemas nacionais, por meio de medidas que fortaleçam a sua competitividade. Os 30 países signatários da Declaração - número que atualmente chega a 47-, respeitando suas realidades institucionais, os sistemas educativos nacionais e a autonomia das universidades, além das especificidades culturais e de línguas, são chamados a coordenar políticas que viabilizem:

1. Um sistema de reconhecimento europeu que torne os diplomas legíveis e comparáveis, favorecendo a integração dos cidadãos no mercado de trabalho internacional e a competitividade do sistema de ensino superior em escala mundial. Esse sistema tem como pilares três ciclos de ensino, a licenciatura ${ }^{1}$, o mestrado² e o doutorado, e é denominado, a partir de então, LMD;

2. Um sistema de créditos (ECTS - European Crédits Transfer System) que promova a mobilidade dos estudantes e valorize os acquis (adquiridos) oriundos da educação ao longo da vida, desde que reconhecidos pelos estabelecimentos de ensino concernidos; 
3. A mobilidade geográfica e institucional de estudantes, professores e pessoal administrativo;

4. A cooperação europeia para a avaliação da qualidade, com a elaboração de critérios e de metodologias comparáveis;

5. A cooperação europeia na elaboração de programas de estudos, entre estabelecimentos, nos programas de mobilidade e nos programas integrados de estudo, de formação e de pesquisa (DÉCLARATION DE BOLOGNE, 1999, p. 3).

Na França, a criação do grau e do diploma de mestrado se dá, portanto, no interior do movimento em favor da criação do espaço europeu do ensino superior e carrega suas marcas. Esse mesmo arcabouço ancora a criação dos mestrados portugueses. Com a constituição desse espaço, as primeiras iniciativas para a reforma do sistema de ensino superior português são de 2005. Implantaram-se o sistema de créditos (ECTS) para ciclos de estudo, os mecanismos de mobilidade e o suplemento ao diploma, entre outras medidas. Efetuaram-se também alterações na Lei de Bases do Sistema Educativo. Em 2006, introduziu-se a nova estrutura em três ciclos de estudo, efetivada integralmente a partir do ano letivo de 2009/10.

Santos (2003) declara que a proposta do Estatuto das Universidades Brasileiras, em 1931, sob a condução do então Ministro da Educação e Saúde Pública, Francisco Campos, marca os primeiros passos da pós-graduação no Brasil. Revela o autor que, à época, modelos europeus influenciaram cursos pós-graduados das antigas Universidade do Rio de Janeiro e Faculdade Nacional de Filosofia e da atual Universidade de São Paulo. Na década de 1940, o termo pósgraduação teria sido utilizado pela primeira vez no País no art. 71 do Estatuto da Universidade do Brasil. Em 1965, com o Parecer n ${ }^{9}$ 977, tem-se um marco da regulamentação da pós-graduação brasileira.

É fundamental registrar a ancoragem da pós-graduação brasileira com a instituição da Capes (Decreto $n^{\circ} 29.741$, de 1951). Inicialmente como Campanha Nacional de Aperfeiçoamento de Pessoal de Nível Superior e, posteriormente, como Coordenação de Aperfeiçoamento de 
Pessoal de Nivel Superior, o órgão vem, desde então, coordenando a expansão e a consolidação da pós-graduação stricto sensu (mestrado e doutorado) brasileira por meio de incentivos diversos e regulação. Pelo Decreto $n^{\circ}$ 86.791, de 1981, a Capes passou a ser responsável pela elaboração, acompanhamento e avaliação da implementação do Plano Nacional de Pós-Graduação. Para tanto, o órgão tem investido no aperfeiçoamento da avaliação da pós-graduação stricto sensu, no acesso e na divulgação da produção científica, em bolsas de estudo no País e no exterior, na promoção da cooperação científica internacional e, recentemente, também na formação inicial e continuada de professores para a educação básica.

A organização e a oferta de cursos de mestrado no Brasil, na França e em Portugal compõem o item seguinte.

\section{Organização e oferta de cursos de mestrado no Brasil, na França e em Portugal}

\section{Brasil}

A obtenção do grau de mestre, no Brasil, requer um conjunto de atividades acadêmicas no qual se inclui a exigência da apresentação de dissertação ou de outro tipo de trabalho de conclusão compatível com as características da área de conhecimento à qual se refere o curso. As instituições podem considerar o mestrado como etapa inicial do doutoramento.

O mestrado é oferecido em duas modalidades: a acadêmica e a profissional. Com base nos dados divulgados pela Coordenação de Aperfeiçoamento de Pessoal de Nivel Superior (Capes) em seu sítio, o total de mestrados brasileiros legalmente reconhecidos chega a 4.248, dos quais 3.674 (86,5\%) são classificados como acadêmicos e 574 (13,5\%) como profissionais.

Ao curso de mestrado acadêmico é atribuída a finalidade de formar pesquisadores, tendo-se a expectativa de que nele o aluno 
cumpra o rito de passagem para o doutorado. Já os mestrados profissionais, conforme o art. $3^{\circ}$ da Portaria Normativa $n^{\circ} 17 / 09$ do Ministério da Educação (BRASIL, 2009), buscam a capacitação profissional avançada para atuação em atividades técnico-científicas e de inovação; a formação pela apropriação e aplicação do conhecimento embasado no rigor metodológico e nos fundamentos científicos; a incorporação e a atualização dos avanços da ciência e das tecnologias, com capacitação para aplicá-los, com foco na gestão, na produção técnico-científica e na pesquisa aplicada; e a proposição de inovações e aperfeiçoamentos tecnológicos para a solução de problemas específicos. Em conformidade com o art. $4^{\circ}$ da referida portaria, conclui-se que os mestrados profissionais focalizam a qualificação profissional apoiada em conhecimentos científicos e tecnológicos, tendo em vista atenderem demandas sociais, organizacionais ou profissionais e do mercado de trabalho, em âmbitos nacional, regional e local, de forma que contribuam para a melhoria da eficácia e da eficiência dos setores públicos e privados, por meio da solução de problemas e inovações em processos e produtos.

No seu art. $5^{\circ}$, a Portaria $n^{\circ} 17 / 09$ estabelece:

Art. $5^{\circ}$ Os cursos de mestrado profissional a serem submetidos à CAPES podem ser propostos por universidades, instituições de ensino e centros de pesquisa, públicos e privados, inclusive em forma de consórcio, atendendo necessária e obrigatoriamente aos requisitos de qualidade fixados pela CAPES e, em particular, demonstrando experiência na prática do ensino e da pesquisa aplicada.

E acrescenta no parágrafo único: “[...] visando o treinamento de pessoal pela exposição dos alunos aos processos da utilização aplicada dos conhecimentos e o exercício da inovação, visando a valorização da experiência profissional".

Cálculos realizados a partir dos dados divulgados pelo sítio da Capes permitem dizer que, atualmente, $65,7 \%$ dos cursos de mestrado profissional no Brasil são oferecidos por instituições públicas. As instituições particulares participam com 34,3\%.

A Portaria Capes $n^{\circ}$ 209/11 contempla, no seu art. $1^{\circ}$, a aprovação do Regulamento do Programa de Mestrado Profissional 
para Qualificação de Professores da Rede Pública da Educação Básica (Proeb), criando, assim, uma linha específica de oferta com o objetivo de conceder apoio à formação continuada em nível de pós-graduação stricto sensu a professores das redes públicas de educação básica e fomentar a manutenção e o desenvolvimento dos programas de pós-graduação e mestrado profissional, para qualificação de docentes do ensino básico das redes públicas, recomendados pelo Conselho Técnico-Científico de Educação Superior da Capes. Para a execução dos cursos, o Proeb prevê apoio financeiro às instituições de ensino superior e bolsas de estudo para alunos.

O prazo para a integralização dos cursos de mestrado no Brasil, independentemente das modalidades acadêmica e profissional, é de, no mínimo, 12 meses e, no máximo, 24 meses. É possível, porém, a prorrogação justificada desse prazo para 30 meses.

\section{França}

À Declaração de Bolonha, sucedeu o Decreto n 99-747, de 30 de agosto de 1999, que cria o grau de mastaire’. A exposição de motivos do parecer encaminhado pelo Ministro da Educação Nacional, da Pesquisa e da Tecnologia ao Primeiro-Ministro francês, visando à aprovação do decreto, apresenta o grau de mestrado "como um novo grau do ensino superior francês. Ele se inscreve no processo iniciado, há um ano, na Sorbonne, pela Alemanha, França, Itália e Reino Unido para construir o Espaço Europeu do Ensino Superior” (JORF, 1999, p. 13106).

De acordo com o Decreto $n^{\circ}$ 99-747/99, o novo grau se junta aos três existentes, o baccalauréat, a licenciatura e o doutorado, situandose entre a licenciatura e o doutorado. Ele reúne, sob uma denominação única, um conjunto de diplomas e títulos, de nível comparável, expedidos em nome do Estado e sob sua garantia: o Diploma de Estudos Superiores Especializados (DESS), o Diploma de Estudos Aprofundados (DEA), títulos de engenheiro e outros. A possessão desses títulos e diplomas se estendeu aos titulares que recorreram a procedimentos de validação de estudos e aquisições, profissionais ou pessoais, levados em consideração os períodos de estudos ou estágios efetuados em um país participante

3 Primeira denominação atribuída ao mestrado. da construção do espaço europeu do ensino superior. 
O grau de mestrado concerne ao ensino superior francês, envolvendo universidades e escolas.

\begin{abstract}
Pela primeira vez, um mesmo rótulo se aplicará às universidades e às grandes escolas, o que, mesmo preservando a identidade de cada um dos componentes do sistema francês de ensino superior, aumentará largamente sua legibilidade e favorecerá o desenvolvimento das cooperações entre universidades e escolas. Além disso, o mastaire dispondo, de agora em diante, de uma notoriedade mundial, abrirá novas perspectivas de mobilidade e de inserção aos estudantes franceses e tornará muito mais atrativos, para os estudantes estrangeiros, as formações e os diplomas franceses (JORF, 1999, p. 13106).
\end{abstract}

Pouco depois, o Decreto $n^{\circ}$ 2002-480, de 8 de abril de 2002, modifica o anterior. Define em seu art. $1^{\circ}$ que, no título e em todas as disposições do Decreto $n^{\circ}$ 99-747/99, a palavra mastaire deve ser substituída pela palavra master(JORF, 2002, p. 6323), opção que sinaliza o interesse em situar o mestrado em uma posição de competitividade em escala mundial.

O Code de l'Éducation ${ }^{4}$ define a organização do ensino superior em ciclos. Os graus de licenciatura, de mestrado e de doutorado são conferidos, respectivamente, no primeiro, segundo e terceiro ciclos.

O segundo ciclo abrange, em proporções diversas, formação geral e formação profissional, conforme o art. L612-5: “Estas formações, organizadas notadamente em vista da preparação para uma profissão ou para um conjunto de profissões, permitem aos estudantes completar seus conhecimentos, aprofundar sua cultura, e os iniciam à pesquisa científica correspondente".

Os diplomas que sancionam a formação de segundo ciclo conduzem à atribuição do grau de mestrado dentro das condições previstas pelos arts. D. 612-34 a D. 612-36 explicitadas a seguir.

O grau de mestrado confere pleno direito aos titulares: 1) de um diploma de mestrado; 2) de um diploma de estudos aprofundados ou um diploma de estudos superiores especializados; 3) de um diploma de engenheiro emitido por um estabelecimento habilitado; 4) de um diploma
4 Reúne leis educacionais francesas. Publicado no Jornal Oficial da República Francesa, em junho de 2000, tem força de lei e é referência para toda a revisão legislativa. 
emitido: a) pelo Institut d'Études Politiques de Paris; b) pelos institutos de estudos políticos; c) pela Université Paris-Dauphine, relativo à Université de Technologie en Sciences des Organisations.

Os diplomas e títulos mencionados acima conduzem ao grau de mestrado, inclusive quando ele resultou da aplicação do procedimento de validação dos adquiridos da experiência 5 .

O grau de mestrado é conferido pelos presidentes ou diretores dos estabelecimentos públicos de caráter científico, cultural e profissional. Outros estabelecimentos de ensino superior público autorizados, sós ou conjuntamente com outros estabelecimentos de ensino superior público francês ou estrangeiro, podem emitir o diploma de mestrado.

O Arreté ${ }^{6}$ de 25 de abril de 2002 (JORF, 2002, p. 7631), referente ao diploma nacional de mestrado, apresenta em seus 19 artigos disposições gerais e disposições particulares relativas às universidades, além de disposições particulares que concernem a certos estabelecimentos de ensino superior, apresentadas em seguida.

O diploma nacional de mestrado confere ao seu titular o grau de mestrado, que corresponde à obtenção de 120 créditos europeus (ECTS). Ele sanciona percursos de formação inicial ou contínua e compreende uma via de finalidade profissional, que concede o mestrado profissional, e outra de pesquisa, que corresponde ao mestrado pesquisa. O diploma tem definidos a sua finalidade e o domínio de formação concernido. Ele é acompanhado de um anexo descritivo e contém a menção do ou dos estabelecimentos que o expediram.

Para se inscrever em uma das formações que conduzem ao

Certas profissões
regulamentadas exigem o grau de mestrado, como psicólogo, administrador judiciário, mandatário judiciário, advogado, engenheiro territorial.

${ }^{6}$ Ato emitido por outra autoridade administrativa que não o Presidente da República ou o PrimeiroMinistro.

7 Mémoire. 
expedição do diploma depende da validação do domínio de pelo menos uma língua viva estrangeira.

Estabelecimentos públicos de caráter científico, cultural e profissional habilitados expedem o diploma de mestrado, sós ou em conjunto com outros estabelecimentos públicos de ensino superior habilitados a expedir diplomas nacionais. Nesse caso, uma convenção define a modalidade da cooperação. A habilitação é definida ou renovada depois de uma avaliação nacional periódica e contém a denominação do diploma, assim como o nome do responsável pela formação. 0 mestrado pode, ainda, ser assegurado por outros estabelecimentos de ensino superior ligados por convenção aos estabelecimentos habilitados a expedir esses diplomas e sob a responsabilidade dos últimos.

O diploma de mestrado permite às universidades organizar o conjunto da sua oferta sob a forma de percursos-tipo que se diferenciam, em geral, após a obtenção dos 60 primeiros créditos ${ }^{8}$ europeus (o $\left(1^{19}\right.$ ): o mestrado profissional e/ou o mestrado pesquisa (o $M 2$, mais 60 créditos). A admissão em mestrado pesquisa vislumbra uma formação posterior em nivel de doutorado e se efetua em condições previstas na legislação. A admissão em mestrado profissional requer o pronunciamento do chefe do estabelecimento, a partir da proposição do responsável pela formação.

Está prevista a orientação progressiva dos estudantes com a oferta de estudos e atividades pedagógicas que Ihes permitam elaborar seu projeto profissional e apreender as exigências dos diversos percursos-tipo propostos. Ela compreende também a construção de passarelas entre esses percursos-tipo. Cada estudante deve se beneficiar de um acompanhamento que assegure sua orientação e a coerência pedagógica de seu percurso.

Cada universidade, por domínio de formação, submete a organização de sua oferta e as denominações propostas à avaliação nacional para fins de habilitação.

O diploma de mestrado pode ser expedido por estabelecimentos de ensino superior submetidos à tutela de outros ministros além
${ }^{8}$ Os créditos substituem a contabilização medida por intermédio da hora/aula. ${ }^{9}$ Corresponde à antiga maitrîse. 
daquele do ensino superior. Nesse caso, ele sanciona um alto nível de competências profissionais. Após uma avaliação nacional periódica, os estabelecimentos são habilitados, sós ou conjuntamente, por uma duração fixada pelo ministro encarregado do ensino superior e outros ministros concernidos, a expedir o diploma de mestrado nos seus domínios de competência.

Atos do ministro do ensino superior e outros interessados fixam, para cada domínio de formação, as modalidades de avaliação nacional periódica a cargo de comissões nacionais de avaliação especializadas.

A política nacional de criação dos diplomas de mestrado visa equilibrar a demanda de formação e a oferta nacional no território e desenvolver harmoniosamente os mestrados, tanto de finalidade pesquisa quanto profissional.

O diploma de mestrado é obtido após a aquisição de 120 créditos capitalizáveis, obtidos em quatro semestres, depois da licenciatura. De organização semestral e modular, ele é classificado em domínios, menções, especialidades e percursos. Cada módulo corresponde a um número de créditos, em razão da carga total de trabalho exigida do estudante em cursos, estágios e trabalho pessoal, além de outros.

O diploma de mestrado é uma exigência para o exercício da profissão docente no ensino fundamental e médio. O mestrado Métiers de I'Enseignement, de l'Éducation et de la Formation (MEEF), criado recentemente, é um diploma nacional emitido pelas universidades e pelas escolas superiores de professores e da educação (ESPE).

O conjunto da oferta de formação no nível do mestrado corresponde às competências específicas de cada instituição, principalmente em termos de pesquisa e inovação.

\section{Portugal}

A legislação portuguesa sobre o $2^{\circ}$ ciclo (cursos de mestrado) tem no Decreto-Lei $n^{\circ}$ 74, de 24 de março de 2006, sua referência 
principal. Esse Decreto-Lei foi sucessivamente alterado e republicado. 0 atualmente em vigor é o Decreto-Lei n ${ }^{\circ}$ 115/13, que incorpora o anterior e as alterações nele efetuadas. Prevê-se que essa oferta seja feita por duas modalidades de instituição de ensino superior, as politécnicas e as universitárias. Somente estas últimas têm a prerrogativa de oferecer o $3^{\circ}$ ciclo (cursos de doutorado). Em Portugal, todas as instituições de ensino superior, para pôr em funcionamento ciclos de estudos, precisam ser acreditadas pela Agência de Avaliação e Acreditação do Ensino Superior e estar registradas na Direção-Geral do Ensino Superior, conforme estabelece $o$ art. 61 da Lei $n^{\circ}$ 62, de 2007. 0 processo de acreditação reporta-se ao conjunto dos recursos humanos e materiais, tais como instalações e equipamentos requeridos para a oferta de cada ciclo de estudos.

0 art. 18 do Decreto-Lei $n^{\circ}$ 74, de 2006, assim diferencia os dois tipos de cursos de mestrado:

3 - No ensino universitário, o ciclo de estudos conducente ao grau de mestre deve assegurar que o estudante adquira uma especialização de natureza acadêmica com recurso à actividade de investigação, de inovação ou de aprofundamento de competências profissionais.

4 - No ensino politécnico, o ciclo de estudos conducente ao grau de mestre deve assegurar, predominantemente, a aquisição pelo estudante de uma especialização de natureza profissional (PORTUGAL, 2006).

Em junho de $2014^{10}$, chegavam a 2.800 os cursos de mestrado autorizados a funcionar em Portugal. São autorizados aqueles que são alvo da acreditação realizada no âmbito do quadro do sistema europeu de garantia de qualidade no ensino superior. A grande maioria é de tipo universitário: 2.012 (71,9\%). O número dos mestrados politécnicos (788, o que representa $28,1 \%$ ) é expressivo, sobretudo considerandose o fato de que foram instituídos muito recentemente, há menos de 10 anos, em 2005. Somados, os cursos de mestrado universitários e politécnicos autorizados encontravam-se, em junho de 2014, em sua maioria $(78,5 \%)$ na rede pública de ensino, com 2.197 cursos. Na rede privada, os 603 restantes $(21,5 \%)$. Os cursos de mestrado portugueses se dividem também em outras duas categorias: os integrados ao $1^{\circ}$ ciclo (licenciaturas) e os oferecidos aos que atendem aos critérios
${ }^{10}$ As estatísticas dessa seção são de junho de 2014 e foram produzidas a partir de números desagregados publicados na Internet pela Direção-Geral do Ensino Superior do Ministério da Educação e Ciência. 
estabelecidos pelo art. 17 do Decreto-Lei $n^{\circ}$ 115/2013, tais como ser titulado em grau de licenciado ou equivalente legal ou ser detentor de um currículo escolar, científico ou profissional que ateste a capacidade para realização desse ciclo de estudos. Os cursos de mestrado oferecidos em ciclo de estudo integrado eram, em junho de 2014, 153 (5,5\% do total), todos do tipo universitário. Os demais eram 2.647 (94,5\%), universitários em sua grande maioria (1.859 ou 70,2\%), e públicos (2.084 ou 78,4\%).

A maioria dos mestrados universitários autorizados encontravase, em junho de 2014, na rede pública: 1.576 cursos (78,3\%). Na rede privada, estavam os 436 restantes $(21,7 \%)$. No conjunto dos universitários encontram-se os cursos que integram o $1^{\circ}$ ciclo e o $2^{\circ}$ ciclo. $01^{\circ}$ ciclo permite o acesso ao grau de licenciado - e se adota uma outra denominação para que não se confunda com a do grau de mestre. Por exemplo, em Psicologia, o $1^{\circ}$ ciclo atribui o título de licenciado em Ciências Psicológicas, e o $2^{\circ}$ ciclo, o título de mestre (em uma das várias especialidades oferecidas). Segundo o art. 19 do Decreto-Lei $n^{\circ}$ 74/06, os integrados se destinam à preparação para o exercício de uma determinada atividade profissional regida por normas legais vigentes na União Europeia ou que apresente certa estabilidade e consolidação nesse espaço político e geográfico. No conjunto dos cursos universitários autorizados para oferta integrada, a significativa maioria encontra-se na rede pública (80,4\%). Entre eles, predominam os das áreas de Engenharia e de Arquitetura. Mas cursos de mestrado universitários integrados são uma pequena minoria (5,5\% do total), sobretudo na rede privada.

Os cursos de mestrado politécnicos, segundo o art. $8^{\circ}$ do Decreto-Lei n 74/06, destinam-se à “formação que visa o exercício de uma actividade de carácter profissional, assegurando aos estudantes uma componente de aplicação dos conhecimentos e saberes adquiridos às actividades concretas do respectivo perfil profissional”. Previsto pela Lei de Bases do Sistema Educativo, de 1973, o ensino superior politécnico foi, de fato, criado em 1997 para oferta de cursos superiores de curta duração, buscando suprir demandas decorrentes da extinção, em 1974, da formação de técnicos de nível médio.

O ensino superior politécnico foi justificado pela legislação educacional portuguesa como mais vocacionado para a prática e para 
o desenvolvimento da capacidade de inovação e de conhecimentos com vistas ao exercício de atividades profissionais, como cursos destinados a responder a demandas regionais e áreas não tradicionais de conhecimento. Ele foi proposto para ser oferecido por escolas superiores especializadas em domínios técnicos, das artes e da educação, principalmente. Quando associadas, essas escolas formam os institutos politécnicos. Elas oferecem o $1^{\circ}$ ciclo do ensino superior (licenciaturas) com duração média de três anos, e, algumas, o $2^{\circ}$ ciclo (mestrados). Não possuem, porém, a prerrogativa de oferecer o $3^{\circ}$ ciclo (doutorado). A origem dessas escolas advém do ensino médio, que era ministrado, até os anos 1970, em institutos comerciais e industriais e em escolas de magistério para o ensino primário e agrícola. O Decreto-Lei n 402/73 estabeleceu as bases para a criação de institutos politécnicos, que vêm se afirmando como centros de formação técnico-profissional destinados a oferecer o ensino superior de curta duração, voltado a problemas concretos, à investigação aplicada, ao desenvolvimento experimental e às demandas de âmbito regional.

A partir dos acordos derivados do chamado Processo de Bolonha, a oferta de ensino superior politécnico foi ampliada para cursos de mestrado. Os cursos de mestrado autorizados de tipo politécnico, em junho de 2014, chegavam a 788, dos quais 621 (78,8\%) são integrantes da rede pública e 167 (21,8\%), da rede privada.

O Decreto-Lei n 74/06, em seu art. 18, define a duração normal dos mestrados: três a quatro semestres. Admite, excepcionalmente, e sem prejuízo de ser assegurada a satisfação de todos os requisitos relacionados com a caracterização dos objectivos do grau e das suas condições de obtenção, dois semestres curriculares de duração. (PORTUGAL, 2006). Isso significa, nos termos do art. 20 do mesmo Decreto-Lei, a integralização de um ciclo de estudos compreendido por:

a) Um curso de especialização, constituído por um conjunto organizado de unidades curriculares, denominado curso de mestrado, a que corresponde um mínimo de 50\% do total dos créditos do ciclo de estudos;

b) Uma dissertação de natureza científica ou um trabalho de projecto, originais e especialmente realizados para este fim, ou um estágio de natureza profissional objecto de relatório final, consoante os objectivos 
específicos visados, nos termos que sejam fixados pelas respectivas normas regulamentares, a que corresponde um mínimo de $35 \%$ do total dos créditos do ciclo de estudos (PORTUGAL, 2006).

Em agosto de 2013, novo Decreto-Lei, o de $n^{\circ}$ 115, operou mudanças em normas do anterior. Entre elas, a substituição dos 35\% do total de créditos do ciclo de estudos a que se refere o art. 20 por um mínimo de 30 créditos. Essa definição, porém, não é aplicável ao ciclo integrado de estudos, resultado da combinação da oferta de licenciaturas ( $1^{\circ}$ ciclo) com mestrados $\left(2^{\circ}\right.$ ciclo).

A duração dos cursos de mestrado apresenta variações conforme o tipo de ensino, politécnico ou universitário (e, neste último, se há integração do $1^{\circ}$ com o $2^{\circ}$ ciclos) e rede pública ou privada. Os dados publicados pela Direção-Geral do Ensino Superior (DGES) do Ministério da Educação e Ciência mostram que a duração do ciclo de estudos integrados (licenciatura + mestrado) varia de 10 a 12 semestres na rede pública e de 10 a 11 semestres nas instituições privadas. Nas duas redes, os ciclos de estudos integrados duram 10 semestres em sua grande maioria: $84,3 \%$ na rede pública e $93,3 \%$ na rede privada.

São também maioria, nas duas redes de ensino, os cursos de mestrado universitários não integrados autorizados, que têm a duração de quatro semestres: $88,7 \%$ nas instituições públicas e $84,7 \%$ nas privadas. A proporção desses mestrados com duração de três semestres é maior $(12,8 \%)$ nas instituições privadas do que aquela encontrada nas públicas $(8,4 \%)$ e praticamente igual $(2,9 \%$ e $2,5 \%$, respectivamente) no caso da oferta desses cursos com duração inferior a três semestres.

Urbano (2011a, p. 98) admite que a mudança decorrente do Decreto-Lei $n^{\circ}$ 513-T/79 da designação de ensino superior de curta duração para ensino superior politécnico veio dar a esses cursos dignidade idêntica ao universitário, embora seus objetivos de formação superior sejam específicos. Entretanto, é importante registrar que os mestrados do ensino politécnico mostram tendência a uma duração mais curta, sobretudo na rede privada. 


\section{Consideracõos finais}

Os dados referentes aos cursos de mestrado nos três países analisados apontam similitudes e diferenças no que diz respeito aos processos de ancoragem, modalidades, oferta pública ou privada e duração.

Os princípios da Declaração de Bolonha relativos à atratividade e à competitividade dos sistemas de ensino superior, em escala mundial, exigem esforços da França e de Portugal no sentido de garantir um nível cada vez mais aprofundado de comparabilidade e equivalência na oferta de mestrados. De certa forma, embora o Brasil não seja signatário dessa Declaração, os cursos de mestrado brasileiros, à luz da lógica da globalização dos mercados de trabalho e de formação, estão também submetidos às contingências dos processos avaliativos e a padrões de qualidade definidos internacionalmente.

Quanto à dependência administrativa das instituições, a França define a oferta dos cursos de mestrado pelas públicas ou, se e quando for o caso, por outros tipos de instituições, desde que chanceladas pelas primeiras. Em Portugal e no Brasil, os cursos de mestrado, acadêmicos ou profissionais, também têm, em sua maioria, sido ofertados por instituições públicas.

No que diz respeito à duração dos mestrados profissionais e acadêmicos, Portugal apresenta variações singulares e diferenças em relação à França, onde a extensão se assemelha à do Brasil, ainda que no caso francês a medida contábil seja o cumprimento de 120 créditos em quatro semestres.

Nos três países, há possibilidade de oferta de cursos de mestrado em regime de associação entre instituições. No Brasil, as associações de instituições brasileiras ou entre estas e estrangeiras devem se pautar pelo cumprimento das exigências de autorização, reconhecimento e renovação de reconhecimento dos cursos de mestrado em geral. As normas brasileiras estabelecem também que, para a emissão de diploma de mestrado por instituição brasileira, é preciso que a defesa da dissertação seja nela realizada. 
Outro aspecto importante da organização de cursos de mestrado nos três países se refere à possibilidade da oferta a distância. Normas brasileiras determinam que essa oferta seja feita exclusivamente por instituições credenciadas pela União para tal fim. Elas devem, ainda, obedecer às exigências estabelecidas para os cursos da modalidade presencial com relação à autorização, ao reconhecimento e à renovação de reconhecimento. Os cursos de mestrado a distância precisam incluir provas e atividades presenciais, além de exames de qualificação e defesas de dissertação ou tese também presenciais, diante de banca examinadora que inclua pelo menos um professor não pertencente ao quadro docente da instituição responsável pelo programa.

Pode-se considerar que a oferta de dois tipos de mestrado, o profissional (politécnico) e o acadêmico (pesquisa/universitário), é o elemento comum entre os países e o que mais suscita debates. No entanto, essas modalidades se concretizam diferentemente em cada país, em instituições de diferentes dependências administrativas, na duração e, sobretudo, no reconhecimento social e político do seu estatuto epistemológico. A indiferenciação quanto ao valor atribuído a cada uma dessas modalidades de cursos apresenta variação nesses países e precisa ser mais pesquisada.

A razão principal que teria levado à oferta binária de cursos de mestrado no Brasil tem a ver com a necessidade "de articular o ensino de pós-graduação com a aplicação profissional em diferentes áreas do conhecimento" (MARTINS; ASSAD, 2008, p. 329). Isto está claro no art. $4^{\circ}$ da Portaria Normativa do Ministério da Educação n 17/09 (BRASIL, 2009). Martins e Assad (2008, p. 329) argumentam que a criação dos mestrados profissionais no Brasil teve o sentido de formar quadros que não estavam orientados fundamentalmente para seguir carreira acadêmica, mas que buscavam na pós-graduação uma formação profissional que os habilitasse a atuar num mercado extra-acadêmico .

A discussão sobre a necessidade da oferta de mestrados profissionais em ensino não foi nada amena. Moreira (2004, p. 131) justifica-os dizendo "que os mestrados acadêmicos atuais não atendem às necessidades dos professores". O autor defende o mestrado 
profissional por considerar que este "exige que, em nenhum instante e de nenhuma forma, estejam separadas a formação profissional a que se dirige e a pesquisa associada ao que ela envolve" (2004, p. 133).

O debate envolve várias questões: qual a finalidade do conhecimento produzido no mestrado acadêmico e no profissional? Qual a relação de ambos com o mundo do trabalho? 0 tipo de trabalho de conclusão de curso, por exemplo, a dissertação no modelo do mestrado acadêmico, atende à estrutura, aos objetivos e às especificidades do mestrado profissional? Em que a dissertação no mestrado profissional precisa se diferenciar? Os processos pedagógicos no mestrado profissional são diferentes do acadêmico em que sentido?

Na França, o mestrado é muito valorizado no mercado de trabalho. Considerado um diploma profissionalizante com uma vertente para a pesquisa, visa a uma inserção profissional de alto nível e permite, como no Brasil, o prosseguimento de estudos no doutorado. Sua natureza profissionalizante não fragiliza e não se sobrepõe ao objetivo de nele integrar a dimensão da pesquisa. Em muitos casos, segundo a opção realizada no interior das universidades, o mestrado reúne as vias profissional e de pesquisa em um mesmo percurso.

De acordo com Urbano (2011a, p. 96), a atual estrutura do ensino superior em Portugal é semelhante àquela encontrada em outros países europeus, o que levaria "a pensar num fenómeno de globalização da institucionalização de um sistema binário no quadro europeu de formação superior".

Segundo a autora (2011a, p. 99-100), em Portugal, a distinção entre ensino universitário e politécnico "vai muito para além do plano normativo. A causa primeira surge com a extinção dos cursos de ensino técnico (de nível médio) e a necessidade de encontrar alternativas para os públicos afectos". Para a autora, a diversificação do ensino superior combinada com a introdução da vertente mais prática e profissionalizante teria vindo como solução política para atender às crescentes demandas por ensino superior, levando-se em conta a origem social dos públicos. 
Na visão de Pacheco (2003, p. 29-30),

Sob uma linha profissionalizante da universidade, algumas decisões da administração central apontam para a necessidade de serem identificadas formações dirigidas ao exercício de profissões, na reflexão sobre cursos de mestrado de perfil profissional, e reforçadas as ofertas de formações secundárias profissionalizantes de curta duração. Tais medidas são muito discutíveis à luz da autonomia das universidades, mas são muito realistas em face do que se pretende em termos de criação de um espaço de excelência europeu, primeiro económico e só depois científico e cultural. A ideia de a universidade se secundarizar com cursos profissionalizantes tem, à partida, muitos comentários críticos, embora se admita que são vias para as universidades captarem recursos financeiros.

Debate-se atualmente em Portugal até que ponto os mestrados do ensino universitário e os do politécnico seriam diferentes. A obtenção do grau de mestre, segundo o art. 15 do Decreto-Lei n 74/06, está condicionada à demonstração de conhecimentos aprofundados e capacidades de compreensão, desenvolvimento e/ou aplicação original dos conhecimentos obtidos. Em ambos os casos, demanda-se a capacidade de compreensão e de resolução de problemas em situações novas e não familiares, em contextos alargados e multidisciplinares, ainda que relacionados com a área de estudo. 0 art. 15 ainda se refere à:

c) Capacidade para integrar conhecimentos, lidar com questões complexas, desenvolver soluções ou emitir juízos em situações de informação limitada ou incompleta, incluindo reflexões sobre as implicações e responsabilidades éticas e sociais que resultem dessas soluções e desses juízos ou os condicionem (PORTUGAL, 2006).

O perfil do mestre, segundo o Decreto-Lei $n^{\circ}$ 74/06, deve ainda ser constituído por capacidade de comunicação clara de conclusões, conhecimentos e raciocínios, seja a especialistas ou a não especialistas, e por disposições favoráveis e auto-orientadas ao aprendizado ao longo da vida. Portanto, ao juízo da legislação, são aplicáveis os mesmos critérios de avaliação de aprendizagens e desempenhos, independentemente de os mestrados serem universitários ou politécnicos.

Araújo (2008, p. 3) considera que "A formação a nível do mestrado em Portugal merece uma análise mais cuidadosa, pois é um grau mais 
generalizado, ao abrigo do modelo de Bolonha”. Urbano (2011a, p. 95) registra que "entre todos os níveis de ensino em Portugal, o ensino superior é talvez aquele que, nas últimas décadas, mais se transformou, sofrendo alterações a nível estrutural, institucional, económico, demográfico e social".

Bilau (2011, p. 1) distingue a vertente universitária como aquela que "privilegia a oferta de formações científicas sólidas, juntando esforços e competências de unidades de ensino e investigação" e a vertente politécnica como a que "visa em especial as formações vocacionais e técnicas avançadas, orientadas profissionalmente". Urbano (2011a, p. 98) destaca as dimensões que "surgem a delinear a fronteira entre os dois subsistemas de ensino superior: os objectivos, a profundidade científica, as componentes teórica e prática, os domínios envolventes". Segundo a autora, "ao universitário estaria reservada a capacidade conceptual e ao politécnico a capacidade pragmática”. Contudo, Urbano (2011a, p. 96) adverte que "pouco ainda se conhece acerca da realidade do ensino superior politécnico, da sua população, das motivações e razões de escolha deste subsistema de ensino, bem como das representações sociais criadas em seu torno". Refere-se a autora também ao aumento da ambiguidade nessas distinções que se apoiam em afirmações do que "é/não é” e revela que

[...] há quem fale em deriva académica dos politécnicos, uma vez que criam cursos existentes nas universidades, e em deriva politécnica das universidades, com a criação de cursos de cariz mais técnico que estariam mais no âmbito não-universitário (2011a, p. 98).

A autora resgata, assim, o surgimento de outros critérios para o estabelecimento das diferenças entre o ensino universitário e o politécnico, tais como: "visão estratégica, dimensão cultural, internacionalização, impacto regional, investigação e desenvolvimento (I\&D), inovação, especialização e interdisciplinaridade" (2011a, p. 98).

E avalia, na sua tese de doutoramento:

A formação de $2^{\circ}$ ciclo em escolas e institutos de ensino politécnico vai sendo aos poucos uma realidade em Portugal e, também, em toda 
a Europa. Essa tendência é resultante das necessidades sentidas pelo mercado de trabalho, em termos de aprendizagens continuadas centradas/orientadas em termos profissionais, cujo foco de análise incida sobre a complexidade da vida laboral actual. E é a centralidade destas questões na formação politécnica pós-graduada, com especial incidência na pesquisa orientada para a prática e a reflexão em torno das práticas profissionais complexas, que impulsionam o aumento de oferta e procura deste tipo de formação (URBANO, 2011b, p. 221).

Em face dessa nova realidade, interroga-se Urbano:

[...] o Processo de Bolonha permitiu ao ensino superior politécnico a construção de novos desafios, até então exclusivamente sob a alçada das unidades de cariz universitário. E perante a possibilidade de o ensino politécnico aceder a dois pelouros exclusivos do subsistema universitário - a formação pós-graduada e a investigação -, faz todo o sentido construir uma nova questão: a partir destes dois vectores adicionais, será definida, por parte do subsistema politécnico, uma nova lógica de posicionamento, actuação, e até mesmo uma nova identidade? (2011b, p. 221).

Para a autora, se, por um lado, a diversificação do ensino superior facilitou o acesso à formação pós-graduada de um público com dificuldade de corresponder aos critérios de seleção das universidades, as classes trabalhadoras; por outro, o risco de fazer aumentar o elitismo do subsistema universitário não estaria descartado.

Retomando Ciavatta (2000, p. 198), o processo de tomar conhecimento do outro e de si próprio tem como implicação "a comparação de si próprio com aquilo que se vê no outro". Espera-se que este artigo contribua para promover em cada leitor - brasileiro, francês, português ou mesmo de outra nacionalidade - elementos para reflexão sobre a pós-graduação e, sobretudo, os cursos de mestrado em que se veem concernidos por suas práticas ou interesses.

Recebido em 09/08/2014 Aprovado em 25/08/2014 


\section{Referências}

ARAÚJO, E. Mestrados em Portugal: tendências e modelos organizativos. In: CONGRESSO PORTUGUÊS DE SOCIOLOGIA, 6, 2008, Lisboa. Mundos sociais: saberes e práticas. Universidade Nova de Lisboa. Faculdade de Ciências Sociais e Humanas. 25-28 jun. 2008. Disponível em: <http:/ / www.aps.pt/vicongresso/pdfs/612.pdf> . Acesso: 16 set. 2014.

BILAU, J. J. Governo e gestão das instituições de ensino superior em Portugal: o caso dos institutos politécnicos. Revista Ibero-Americana de Educação, n. 55/2, 15 mar. 2011.

BRASIL. Lei de Diretrizes e Bases da Educação Nacional n 9.394, de 20 de dezembro de 1996. Estabelece as diretrizes e bases da educação nacional. Diário Oficial [da] República Federativa do Brasil, Poder Executivo, Brasília, DF, 23 dez. 1996.

Parecer n CFE 977/65, de 3 de dez. de 1965. In: Legislação e Normas da Pós-graduação Brasileira. Funadesp. Brasília, 2001.

Portaria $n^{\circ}$ 17, de 28 de dezembro de 2009. Diário Oficial [da] República Federativa do Brasil, Poder Executivo, Brasília, DF, 29 dez. 2009. Seção 1, p. 20-21.

Portaria $n^{\circ}$ 209, de 21 de outubro de 2011. Diário Oficial [da] República Federativa do Brasil, Poder Executivo, Brasília, DF, 26 out. 2011. Seção 1, p. 14.

. Resolução CNE/CES n 1, de 3 de abril de 2001. Diário Oficial [da] República Federativa do Brasil, Poder Executivo, Brasília, DF, 3 abr. 2001. Seção 1, p. 12.

Resolução n. 5, de 10 de março de 1983. Diário Oficial [da] República Federativa do Brasil, Poder Executivo, Brasília, DF, 10 mar. 1983. 
CAPES - Coordenação de Aperfeiçoamento de Pessoal de Nivel Superior. Portaria $n^{\circ}$ 47, de 17 de outubro de 1995. RBPG, v. 2, n. 4, p. 147-148, jul. 2005.

CIAVATTA, M. Quando nós somos o outro: questões metodológicas sobre os estudos comparados. Educação \& Sociedade, ano XXI, n. 72, p.197230, ago. 2000.

CONFERENCE DES MINISTRES EUROPEENS CHARGES DE L'ENSEIGNEMENT SUPERIEUR. Déclaration de Bologne, 19 juin, 1999, $p$ 3. Disponivel em: <http:www.sup.adc.education.fr/europedu/french/ index.html>. Acesso em: 20 jul. 2014.

FRANÇA. Arrêté de 25 de abril de 2002. Journal Officiel de la République Française-JORF, Ministère de I' Éducation National de I' Enseignement et de la Recherche, Paris, n 99, 27 abr., 2002, p. 7631. Disponivel em: <http://www.legifrance.gouv.fr/affichTexte. do?cidTexte=JORFTEXT000000771847\&dateTexte=\&categorieLien=id $>$. Acesso em: 28 jul. 2014.

Decreto $n^{\circ}$ 99-747, de 30 de agosto de 1999. Journal Officiel de la République Française-JORF, Ministère de l'Éducation National de I' Enseignement et de la Recherche, Paris, $n^{\circ} 203,2$ sept. 1999, p. 13106. Disponivel em: <http://www.legifrance.gouv.fr/>. Acesso em: 24 jul. 2014.

Decreto $n^{\circ}$ 2002-480, de 8 de abril de 2002. Journal Officiel de la République Française-JORF, Ministère de l'Éducation National de I'Enseignement et de la Recherche, Paris, nº 0084, 8 avril 2002, p. 6323, texte $n^{\circ}$ 34. Disponivel em: <http://www.legifrance.gouv.fr/>. Acesso em: 24 jul. 2014.

Rapport au Premier ministre relatif au décret $n^{\circ}$ 99-747 du 30 août 1999 relatif à la création du grade de mastaire. Journal Officiel de la République Française-JORF, Ministère de I'Éducation National de I' Enseignement et de la Recherche, Paris, n² 203, 2 sep. 1999, p. 13106. Disponivel em: <http://www.legifrance.gouv.fr/>. Acesso em: 24 jul. 2014 
KRAWCZYK, N. Pesquisa comparada em educação na América Latina: situações e perspectiva. Educação Unisinos, v. 17, n. 3, p.199-204, set./ dez. 2013.

MARTINS, C. B. M.; ASSAD, A. L. D. A pós-graduação e a formação de recursos humanos para inovação. RBPG, Brasília, v. 5, n. 10, p. 322-352, dez. 2008.

MOREIRA, M. A. O mestrado (profissional) em ensino. RBPG, Brasília, v. 1, n. 1, p. 131-142, jul. 2004.

PACHECO, J. A. Políticas educativas para o ensino superior na União Europeia: um olhar do lado português. Educ. Soc., Campinas, v. 24, n. 82, p. 17-36, abr. 2003.

PORTUGAL. Ministério da Ciência, Tecnologia e Ensino Superior. DecretoLei n. ${ }^{\circ}$ 74/2006, de 24 de Março. Diário da República, $1^{\text {a }}$ série - A, n. 60, 24 de março de 2006. Disponível em: <http://www.dre.pt/pdf1sdip/2 006/03/060A00/22422257.PDF>. Acesso em: 15 jul. 2014.

Ministério da Educação e Ciência. Decreto-Lei n 115/2013, de 7 de agosto. Avaliação da aplicação dos diplomas estruturantes do ensino superior e a sua revisão e melhoria nos aspetos que se revelem deficientes. Diário da República, $1^{\text {a }}$ série, n. 151, 7 de agosto de 2013. Disponivel em: <http://www.a3es.pt/sites/default/files/DL\%20 115_2013\%20GADES.pdf>. Acesso em: 15 jul. 2014.

Ministério da Educação Nacional. Decreto-Lei n 402/1973, de 11 de agosto. Cria novas Universidades, Institutos Politécnicos e Escolas Normais Superiores, define o regime das suas comissões instaladoras e adopta providências destinadas a assegurarem o recrutamento e a formação do pessoal necessário para o início das respectivas actividades. Diário da República, $1^{\text {aa }}$ série, n. 188/73, 11 ago. 1973.

SANTOS, C. M. Tradições e contradições da pós-graduação no Brasil. Educ. Soc., Campinas, v. 24, n. 83, p. 627-641, ago. 2003. Disponível em: <http://www.cedes.unicamp.br>. Acesso: 8 ago. 2014. 
URBANO, C. A (id)entidade do ensino superior politécnico em Portugal. Da Lei de Bases do Sistema Educativo à Declaração de Bolonha. Sociologia, Problemas e Práticas, n. ${ }^{\circ}$ 66, 2011a, p. 95-115.

O ensino politécnico em Portugal: a construção de uma identidade perante os desafios de mudança (entre o final do século XX e o início do século XXI). 2011. 414f. Tese (Doutorado) - Universidade Nova de Lisboa. Faculdade de Ciências Sociais e Humanas, Lisboa, 2011b. 